\title{
Perceptions of Teachers towards the Implementation of Task- Based Language Teaching: A Case Study in a Vietnamese University
}

\begin{abstract}
Dao Thi Thanh Hao (MA)
International Education Center, Hanoi University, Km9, Nguyen Trai, Thanh Xuan, Hanoi, Vietnam

Abstract: The current study investigates the perceptions of teachers at a state university where English is the medium of instruction towards the implementation of task-based language teaching (TBLT). The instrument namely questionnaire was designed to collect data from 55 participants. The findings suggested that most of the teachers had practical understanding about the key features of task and TBLT, and they hold the positive views on the TBLT implementation. The data also identified exam preparation as the biggest obstacle for Vietnamese university teachers when adopting TBLT. Based on the findings, a number of pedagogical recommendation for teachers and educators were put forward in an attempt to improve the curriculum design and implementation as well as assessment for better communicative competence of Vietnamese students.
\end{abstract}

Keywords: Perception, Task-based language teaching, communicative competence, University teachers.

\section{INTRODUCTION}

Since the introduction of the communicative language teaching (CLT) approach in the early 1980s and much highlight on learners' communicative competence over the past decades, the term taskbased language teaching (TBLT) has grown in popularity in the field of second language acquisition. Within the varying interpretations of TBLT related to classroom practice, most studies are of the agreement that the core feature of tasks is their focus on the communication of meaning. In Vietnam, like other EFL contexts teachers, especially those at the tertiary level have experienced a variety of methods and approaches of English teaching and learning, from traditional grammar-translation method to CLT and TBLT [1]. However, not many studies so far have been conducted to investigate the perceptions of teachers towards TBLT and difficulties affecting their avoidance of this approach in Vietnamese tertiary context. This study, hence, is in the field of English language education in Vietnam's Universities, focusing on teachers 'perceptions of TBLT related to ways such perceptions impact on their teaching practices.

Stemming from the constructivist learning theory and CLT methodology, the advent of TBLT is the response to certain limitations of the traditional PPP approach, represented by the procedure of presentation, practice, and performance [2,3]. There exist a number of definitions of what constitutes a "task" among different researchers, linguists, and educators. Willis states that tasks are "always activities where the target language is used by the learners for a communicative purpose (goal) in order to achieve an outcome" [4- 24]. Breen owns a broader definition of task in that a task is "any structural language learning endeavor which has a particular objective, appropriate content, a specified working procedure, and a range of outcomes for these who undertake the task" [5-67]. Richards, Platt, and Weber view TBLT in a more linguistic and pedagogical way when assuming a task as "an activity or action which is a result of understanding and processing the target language" [6- 289]. By gate et al conceptualizes a task as "an activity which requires learners to use language, with emphasis on meaning, to attain an objective, and which is chosen so that it is most likely to provide information for learners which will help them evaluate their own learning" [7-11]. Nunan's definition of task is "a piece of classroom work that involve learners in comprehending, manipulating, producing or interacting in the target language"[8-4]. Meanwhile, Ellis claims that a "task is a work plan that requires learners to process language pragmatically in order to achieve an outcome that can be evaluated in terms of whether the correct propositional content has been conveyed" [2-16].In short, 
across the variety of definitions of tasks presented, some crucial features have been emphasized: task have a work plan related to the real world, focus on meaning, involve cognitive processing, and have a clear defined communicative outcome.

In many Asian countries, the increasing body of research in teaching area has focused on teacher beliefs. However, the studies investigating teacher beliefs about TBLT in EFL countries are often focused on how public teachers think about government policy moves towards a TBLT curriculum, rather than how they are approaching the teaching of it [9]. In Hong Kong for example, Carless's findings revealed while there was a variety of reactions towards the implementation of TBLT among secondary school teachers, the most popular reason for them to avoid TBLT was the complexity in carrying out the tasks in their class [10]. In China, Hu discovered that teachers' attitudes towards TBLT ranged from negative avoidance, through passive acceptance, to more active adoption [11]. Many in 30 teachers in Hu's survey did not use TBLT as it was not an effective method of preparing for their students' examination. This is also the main factor that inhibited the application of TBLT in South Korea[12].In another Korean case study of Jeon and Hahn , the two researchers found that teachers refused to adopt TBLT approach in their class due to the lack of knowledge about TBLT as well as the concerns about the learners to whom the approach was not familiar [13]. This appears to be in consistent with what Cheng and Moses investigated in their study with 132 secondary school teachers [14]. Although most of the participants held a positive reactions towards TBLT, those who refused to employ the approach confessed that they lacked self-confidence in implementing and evaluating the students' outcomes. In Japan, by contrast, TBLT is being used as a powerful tool for teaching English and teachers are well aware of the central tenets of TBLT for effective language teaching in secondary and tertiary education contexts [9]. In Vietnam, the perceptions of teachers about the implementation of TBLT at tertiary level has not been well documented so far, therefore, it is significant for this current study to be conducted to investigate some issues related to teachers' understanding of TBLT, teachers' attitudes towards TBLT, and the challenges they experienced when implementing TBLT in their class. With this in mind, three research questions guided the analysis as follows:

(1) What perceptions do university teachers hold about TBLT?

(2) Whatareuniversityteachers'attitudestowardstheimplementationofTBLT?

(3) What are challenges that inhibit teachers' use of TBLT in class?

\section{METHOD}

\subsection{Participants}

The subjects of this study were 55 teachers $(\mathrm{N}=55), 31$ females $(56.4 \%)$ and 24 males $(43.6 \%)$ at Hanoi University located in the North of Vietnam. The teachers' age ranged from 26 to 52. These teachers taught English for different kinds of students in different programs. Some taught General English with the focus on four main skills namely speaking, listening, reading, and writing. Others taught ESP (English for specific purpose) like tourism, accountancy, business, translation and interpretation. Their teaching experience varied from up to 5 years $(n=16,29.1 \%), 6$ to 10 years $(n=$ $19,34.5 \%), 11$ to 20 years $(n=17,31 \%)$, and more than 20 years $(n=3,5.4 \%)$. It can be implied that these teachers have had time to experiment and practice various teaching styles, reflect on the success and failures in class and so were able to provide responses to the survey questions.

\subsection{Instrument}

The instrument to collect data in response with three predetermined research questions was a questionnaire adapted and developed from Jeon and Hahn [9] (see Appendix). The questionnaire consists of four domains. The first one was to obtain teachers'demographic information; the second part was the investigation of teachers" belief of TBLT; the third domain focused on figuring out teachers' attitudes towards TBLT. All of three domains using five-point scale ranging from "Strong Disagree" to "Strong Agree" to measure the participants' responses. Finally, the last section identifies different challenges posed for teachers when working with TBLT. In this section, the participants rated their choices from the given items.

\subsection{Data Collection and Analysis}

The survey was administered online for the convenience of the respondents and low cost for the researcher. Justification of online survey use was also because respondents might feel more willing and comfortable to share information without the attendance of the researcher. The link to the online 
questionnaire was sent to 87 teachers at Hanoi University via their emails.55 teachers $(63,2 \%)$ sent back their responses. After the answered files returned to the researcher, they were put ID numbers to be easily checked later in case any problems happened to the database. All the data collected were carefully coded and analyzed under the adoption of the software SPSS (statistical package for social sciences) version 16.0 for Windows.

\section{FINDINGS}

\subsection{Teacher Perceptions about TBLT}

Table 1 illustrates the findings of section 2 of the questionnaire that aimed to probe the teachers' understanding about task and TBLT. The outstanding statistic was written in bold for easy recognition.

Table1. Teacher understanding about $\operatorname{TBLT}(n=55)$

\begin{tabular}{|l|l|l|l|l|l|}
\hline \multirow{2}{*}{ Questionnaire items } & \multicolumn{2}{l}{ Frequency $(\%)$} & \multicolumn{3}{l|}{} \\
\cline { 2 - 7 } & SD & $\mathrm{D}$ & $\mathrm{U}$ & $\mathrm{A}$ & $\mathrm{SA}$ \\
\hline 1. A task is a communicative goal direct & 1.8 & 5.5 & 14.5 & $\mathbf{4 9 . 1}$ & $\mathbf{2 9 . 1}$ \\
\hline 2. A task involves primary focus on meaning & 3.6 & 9.2 & 21.8 & $\mathbf{3 8 . 2}$ & $\mathbf{2 7 . 3}$ \\
\hline 3.A task has a clear defined outcome & 0 & 0 & 14.5 & $\mathbf{4 5 . 5}$ & $\mathbf{4 0}$ \\
\hline $\begin{array}{l}\text { 4.A task is an activity in which the target language is } \\
\text { used by the learners }\end{array}$ & 0 & 16.4 & 21.8 & $\mathbf{4 7 . 3}$ & $\mathbf{1 4 . 5}$ \\
\hline $\begin{array}{l}\text { 5.TBLT is in line with the principle of communicative } \\
\text { language teaching }\end{array}$ & 1.8 & 34.5 & 18.1 & $\mathbf{4 0}$ & $\mathbf{5 . 5}$ \\
\hline $\begin{array}{l}\text { 6.TBLT is based on student-centered instructional } \\
\text { approach }\end{array}$ & 0 & 12.7 & 20 & $\mathbf{4 3 . 6}$ & $\mathbf{2 3 . 6}$ \\
\hline $\begin{array}{l}\text { 7.TBLT includes three stages: pre-task, task } \\
\text { implementation, and post-task }\end{array}$ & 0 & 5.5 & 16.4 & $\mathbf{4 1 . 8}$ & $\mathbf{3 6 . 4}$ \\
\hline $\begin{array}{l}\text { 8.Material used with TBLT approach should be based } \\
\text { on the real-world contexts }\end{array}$ & 0 & 7.3 & 12.7 & $\mathbf{3 5 . 4}$ & $\mathbf{4 3 . 6}$ \\
\hline 9.TBLT should be used for high-level students only & 3.6 & $\mathbf{3 2 . 7}$ & $\mathbf{2 1 . 8}$ & $\mathbf{2 5 . 5}$ & 16.4 \\
\hline $\begin{array}{l}\text { 10.Language use in classroom task should be } \\
\text { restricted to L2 only }\end{array}$ & 0 & 18.2 & $\mathbf{2 3 . 6}$ & $\mathbf{5 2 . 7}$ & 5.5 \\
\hline
\end{tabular}

SD: Strongly Disagree, D: Disagree, U: Undecided, A: Agree, SA: Strongly Agree

As can be seen in the table, the first four items examined the understanding of teachers about the task. An overwhelming proportion of the subjects agreed and strongly agreed that a task is a communicative goal direct (78.2\%), involves primary focus on meaning $(65.5 \%)$, has a clear defined outcome (85.5\%), and is an activity in which target language is used by learners (61.5\%). Items from 5 to 7 related to the key concepts of TBLT in language classroom. In response to item 5, almost half of the teachers understood that the approach is consistent with the principle of communicative language teaching. Regarding item 6 "TBLT is based on student-centered instructional approach", $67.2 \%$ showed their agreement and strong agreement with this, while $12,7 \%$ did not share the same opinion, and exactly $20 \%$ could not make up their mind about the statement. When it comes to item $7,78.2 \%$ were for the idea that TBLT consists of three stages namely pre-task, task implementation, and posttask. Item from 8 to 10 mentioned the condition under which TBLT can be adopted. In response to item 8 , most of the participants believed that materials used with task-based approach should be realworld based (79\%). As with item 9, 36.3\% of teachers disagreed that TBLT should be used for highlevel students, $21.8 \%$ gave undecided answer. Meanwhile, up to $25.5 \%$ agreed and $16.4 \%$ strongly agreed with the statement. Item 10 collected $52.7 \%$ agreement opinion, and less comparative $18.2 \%$ disagreement about that TBLT should be restricted to L2 only. Meanwhile, 23.6\% people did not decide their choice.

\subsection{Teacher Attitudes towards TBLT}

The attitudes of teachers were reflected in the table 2 as followed. 
Table2. Teacher views towards execution of TBLT $(n=55)$

\begin{tabular}{|l|l|l|l|l|l|}
\hline Questionnaire Items & \multicolumn{4}{l|}{ Frequency (\%) } \\
\cline { 2 - 6 } & SD & D & U & A & SA \\
\hline 11.I have interest in implementing TBLT & 9 & 14.5 & $\mathbf{3 0 . 9}$ & $\mathbf{3 7 . 5}$ & $\mathbf{8 . 1}$ \\
\hline $\begin{array}{l}\text { 12.TBLT provides a relaxing atmosphere to promote the target } \\
\text { language use }\end{array}$ & 3.6 & 9.1 & 10.7 & $\mathbf{5 5}$ & $\mathbf{2 1 . 6}$ \\
\hline 13.TBLT activates learners' needs and interests & & & & & \\
\hline 14.TBLT pursues the development of integrated skills & 0 & 9.1 & 9.1 & $\mathbf{5 6 . 2}$ & $\mathbf{2 5 . 4}$ \\
\hline $\begin{array}{l}\text { 15.TBLT facilitates a collaborative learning environment in } \\
\text { language classes }\end{array}$ & 0 & 0 & 5.5 & $\mathbf{6 3 . 7}$ & $\mathbf{3 0 . 8}$ \\
\hline 16.Vietnamese learners do not respond well to the adoption of TBLT & $\mathbf{2 1 . 8}$ & $\mathbf{2 5 . 5}$ & $\mathbf{2 7 . 2}$ & 14.2 & 11.3 \\
\hline 17.TBLT should be adapted to be suitable with Vietnamese learners & 0 & 9.1 & 18 & $\mathbf{3 6 . 5}$ & $\mathbf{3 6 . 4}$ \\
\hline
\end{tabular}

SD: Strongly Disagree, D: Disagree, U: Undecided, A: Agree, SA: Strongly Agree

In light of table 2, most of the teachers had positive view on TBLT implementation and a firm belief in the benefits that TBLT could bring to their students. Up to $45.6 \%$ respondents had agreement and strong agreement feedback that they are interested in applying TBLT in their class, $76.6 \%$ thought the approach provides a relaxing atmosphere to encourage target language use. As regards item 13 that "TBLT activates learners' needs and interests", while just over $47 \%$ teachers showed their support, $21.8 \%$ opposed the statement and $23.6 \%$ undecided. In response to item 14 and item 15, a dominating proportion of teachers had positive view that TBLT pursues the development of integrated skills and facilitates a collaborative environment in language class $(81,6 \%$ and $94.5 \%$ respectively). The findings for item 16 indicated that almost half of the teachers disagreed that Vietnamese learners do not respond well to the adoption of TBLT, $27.2 \%$ undecided, and only $25.5 \%$ gave the agreement opinion. For item 17, more than 70\% believed that TBLT should be better adapted to be suitable with Vietnamese learners.

\subsection{Challenges in the Implementation of TBLT}

Table3. Difficulties in the implementation of TBLT $(n=55)$

\begin{tabular}{|l|l|}
\hline Questionnaire items & Frequency (\%) \\
\hline 18.TBLT requires much preparation time compared to other approaches & $\mathbf{6 7 . 2}$ \\
\hline 19.TBLT gives much psychological burden for teachers as facilitators & 41.8 \\
\hline 20.Materials in the text book are not proper to use TBLT & 21.8 \\
\hline 21.Large class size is an obstacle to use TBLT & $\mathbf{6 1 . 8}$ \\
\hline 22.I have difficulties in assessing learner task-based performance & 40.1 \\
\hline 23.I have limited target language proficiency & $\mathbf{5 . 5}$ \\
\hline 24.I have little knowledge of TBLT & 20 \\
\hline 25.TBLT is not useful for exam preparation & $\mathbf{7 0 . 9}$ \\
\hline 26. Others & 16.3 \\
\hline
\end{tabular}

Table 3 illustrates the responses to the question about the challenges facing teachers during their practice of TBLT. The findings collected revealed that the most popular difficulty for them when implementing TBLT was that it is not useful for exam preparation (70.9\%). Much preparation time and large class size received the second and third highest percentage of votes $(67.2 \%$ and $61.8 \%$ respectively). Almost equal proportion of teachers identified the issue of psychological burden and assessment of learner task-based performance as the reasons for their reluctance of conducting TBLT (around $40 \%$ ). Only a tiny percentage (5.5\%) confessed that they lack target language proficiency.

\section{DisCUSSION}

Several important findings from the current study deserve further discussion. First, the data from item 1 to 10 indicate teachers' high level of understanding about core features of task and TBLT. The reason that might help to explain this phenomenon is the advent of ambitious Vietnamese National Project 2020 under which a paradigm shift towards communicative language teaching methodology is encouraged. As such, teachers are advised to apply task-based learning and activity-oriented language use in order to enhance the communicative competence of the learners.

Second, in accordance with teachers' practical knowledge of key concepts of TBLT comes their positive attitudes towards the approach. They own firm belief in the advantages that TBLT brings to 
their students. Yet, most of the subjects in the study agreed that TBLT should be well adapted to be more suitable with Vietnamese context. This results from the fact that Vietnamese students have been more familiar with the traditional teaching and learning methods in which the primary focus is on forms rather than meaning for quite a long time, and their learning goals as well as context might also be different from those in other countries. Therefore, the adaption of TBLT is crucial to gain success in the implementation. Harris [9] also obtained the similar findings about Japanese teachers' views on TBLT since more than $80 \%$ subjects in his study agreed that the approach imported from abroad needs some important adaption.

Where the third research question is concerned, the biggest challenge posed for the teachers is the appropriateness of TBLT to the examination preparation. Another serious concerns are the time of preparation and the large class size. This may result in the fact that most of Vietnamese teachers, like other Asian ones at tertiary level still use traditional method such as grammar translation in the language class rather than TBLT or other CLT methods $[15,16]$. This is consistent with Canh's findings in that although Vietnamese teachers take a positive view on CLT, they find it reluctant and hard to use this approach in practices [17].

\section{Pedagogical implications}

Overall findings of the study has shed light on the execution of TBLT in the context of Vietnamese universities. First, it is crucial for teachers to have adequate knowledge on the instructional framework related to TBLT plan, process, and assessment to gain success in conducting TBLT in their language class. This is congruous with Jeon and Hahn [9] in that a task unnecessarily enables its successful implementation unless the teachers understand how task actually works. Therefore, it is useful for university teachers to attend different workshops or in-depth training to exchange and acquire knowledge about this teaching approach. Once teacher understanding and beliefs in the benefits of TBLT for learners increase, this will motivates them to use this approach in their class to provide learners with effective learning environment so that learners can be more exposed to the target language. This is obviously important for Vietnamese students since they lack much contact with native speakers.

Second, the findings from the current study also revealed several difficulties teachers experience when adopting TBLT. The most popular challenge recorded is that TBLT is not appropriate for exam preparation. This matter seems to be beyond the hands of the language teachers and needs top-down policy changes. Though there are many examples of cases in which teachers successfully adopt TBLT approaches for discreet-item tests $[18,19,20]$, the problem related to exam preparation is still among highlighted reasons that many teacher avoid using TBLT in the language class. Therefore, it is suggested that Vietnamese authority and educators should implement vital policy shift from summative assessment to formative assessment that emphasizes on meaning and methods to encourage and enable TBLT approach to be widely applied in different educational settings included universities.

\section{LIMITATIONS}

Although the study yields some valuable findings related to the execution of TBLT in Vietnamese university context, it does own several shortcomings that need revising in future research. First, it was conducted to investigate the beliefs and views of teachers on TBLT implementation but only quantitative research instrument was used to collect data. The existence of qualitative interviews with teachers to dig deep on their thinking and opinions rather than the given items in the questionnaire would help increase the reliability of the data. Second, notably, the context the participants in this study might be different from that of teachers in other universities, for example, in terms of class size, teachers' authority, and language proficiency. Therefore, the findings from this study may not be well generalized to other teachers in other settings. As such, a larger scaled study needs to be implemented in the future so that Vietnamese teacher perceptions to TBLT can be properly explored.

\section{Conclusion}

Conclusively, the subjects in this study own high level of understanding about the tenet of task and TBLT, and in tandem with this come their positive attitudes towards this approach. They believe in the benefits that the approach brings to their students so they are using TBLT as an effective tool to 
promote students 'communicative ability. However, several obstacles hindering their adoption of TBLT in language class need to be taken into thorough consideration. As to the findings of the study, the biggest problem facing Vietnamese teachers is the appropriateness of TBLT to the exam preparation despite the fact that they appreciate the importance of communicative goal rather than discrete item study for test purpose. This implies that endeavor from both teachers and top-down educators are definitely needed to make the implementation of TBLT in language classrooms in Vietnam less challenging than it is thought. After all, the study is of significance since understanding teachers' perceptions of TBLT seems to be the first step toward reflection and assessment on the execution of TBLT to EFL instruction [21]. This also delineates a bright scenario for teachers to design and carry out any real communicative tasks and at the same time contributes to facilitating EFL teachers' practical use of TBLT techniques to promote the learners' communicative competence.

\section{REFERENCES}

[1] TuyenL. V., Factors affecting task-based language teaching from teachers' perspective, Study in English Language Teaching. 2(1), 108-122 (2014).

[2] Ellis R., Task-based language learning and teaching, Oxford: Oxford University Press, 2003, p.16.

[3] Long M., and Crookes G., Three approaches to task-based syllabus design, TESOL Quarterly.

[4] 26(1), 27-56 (1991).

[5] Willis J., A framework for task-based learning. Harlow: Longman, 1996, p.24.

[6] Breen M., The evaluation cycle for language learning tasks, In Johnson, R.K. Edition. The second language curriculum, Cambridge: Cambridge University Press, 1989,p.67.

[7] Richards J. C., Platt J. and Weber H., Longman Dictionary of Applied Linguistics London.

[8] Harlow U.K: Longman Addison- Wesley, 1986, p.289.

[9] Bygate M., Skehan P., and Swain M., Researching pedagogical tasks: Second language learning, teaching, and testing, Longman: Harlow, 2001, p.11.

[10] Nunan D., Task-based Language Teaching, Cambridge: Cambridge University Press, 2004, p.4. [9] Harris J., Teachers' beliefs about task-based language teaching in Japan, The Journal of Asia TEFL.13(2), 102-116(2016).

[11] Carless D., Issues in teachers' re-interpretation of a task-based innovation in primary schools, TESOL Quarterly.38 (4), 639-662(2004).

[12] Hu R., Task-based language teaching: Responses from Chinese teachers of English, TESL_EJ, the Electric Journal for English as a Foreign Language. 16(4),1-21(2013).

[13] Li D.,It's always more difficult than you planned: Teachers' perceived difficulties in implementing the communicative approach in South Korea TESOL Quarterly. 32(4), 677-703 (1998).

[14] Jeon I., and Hahn J., Exploring EFL teachers' perceptions of task-based language teaching: A case study of Korean secondary school classroom practice, Asian EFL Journal. 8(1), 123-139 (2006).

[15] Cheng X., and Moses S., Perceptions and implementation of task-based teaching among secondary school EFL teachers in China, International Journal of Business and Social Science.2 (24), 292-302(2011).

[16] Tang L.Y. E., Task-based learning in the Asian classroom, Guidelines. 26(1), 14-18 (2004).

[17] Tong S., Task-based learning in English language in Hong Kong secondary schools. HKU thesis online (HKUTO), (2005). (Thesis style).

[18] Canh L.V., Language and Vietnamese Pedagogical Context, Teacher's Edition, 34-40, (2001). Finch A.,Students as test-makers, Modern English Education. 6(2), 3-25 (2005).

[19] Harris J., Four TBLT projects for the CALL classroom, JALT CALL conference, Fukuoka, Japan, (2011). (Conference proceedingstyle).

[20] Littlewood W., Communicative and task-based language teaching in East Asian classrooms, Language Teaching. 40(3), 243-249 (2007).

[21] Hui O. L., Teachers' perceptions of task-based language teaching: Impact on their teaching approaches. The HKU Scholars Hub. The University of Hong Kong, (2004). (Conference proceeding style). 


\section{AUTHOR'S BIOGRAPHY}

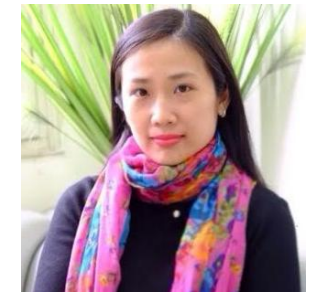

Ms. Dao Thi Thanh Hao, has been working as a teacher of English at International Education Center (IEC), Hanoi University (HANU) for 8 years. From 2012 to 2014, she has done Master of TESOL from Victoria UniversityAustralia. Since her University graduation with High Distinction Degree in 2008, she is employed by Hanoi University and has taught English for different kinds of students of all levels from elementary to advanced at IEC. During this time, she has attended various short training courses about TESOL for teachers held by US embassy, Australia embassy as well as Vietnamese Government. She is now a $\mathrm{PhD}$ candidate. Her research interests are task-based language teaching and communicative language teaching.

APPENDIX

\section{ONLINE TEACHER SURVEY}

The purpose of this questionnaire is to collect information on the perceptions and attitudes of teachers towards the implementation of TBLT in Vietnamese tertiary context. All information will be confidential. There are no foreseeable associated risks involved in the project other than inconvenience. Thank you for taking the time to answer thoughtfully and sincerely these questions.

\section{PART I: GENERAL INFORMATION}

1. Name:

2. Sex:

3. Age:

4. How many years have you taught English? (Please tick in thegrid)
Under 5years
6 to10 years
11 to20years
More than 20years

\section{PART II: TEACHERS' UNDERSTANDING OF TASK AND TBLT}

Please tick your choice in the grid according to the scale: SD (strongly disagree), D (disagree), U (undecided), A (Agree), SA (strongly agree).

Questionnaire items

SD D U A SA

1. A task is a communicative goal direct

2. A task involves primary focus onmeaning

3. A task has a clear defined outcome

4. A task is an activity in which the target language is used by the learners 5 .

TBLT is in line with the principle of communicative language teaching

5. TBLT is based on student-centered instructionalapproach

6. TBLT includes three stages: pre-task, task implementation, andpost-task

7. Material used with TBLT approach should be based on the real-world contexts

8. TBLT should be used for high-level studentsonly

9. Language use in classroom task should be restricted to L2only

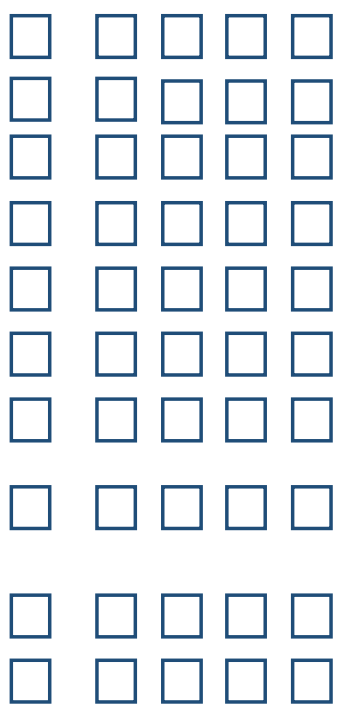

PART III: TEACHERS' ATTITUDES TOWARDS TBLT

Please tick your choice in the grid according to the scale: SD (strongly disagree), D (disagree), U (undecided), A (Agree), SA (strongly agree). 
Questionnaire Items

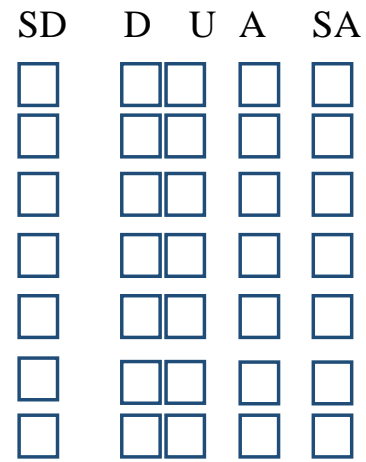

11. I have interest in implementing TBLT

12. TBLT provides a relaxing atmosphere to promote the target language use

13. TBLT activates learners' needs and interests

14. TBLT pursues the development of integrated skills

15. TBLT facilitates a collaborative learning environment in language classes

16. Vietnamese learners do not respond well to the adoption of TBLT

17. TBLT should be adapted to be suitable with Vietnamese learners

\section{PART IV: CHALLENGES IN IMPLEMENTING TBLT IN VIETNAM}

Please tick the statement(s) you think are the challenges in implementing TBLT in Vietnamese context. You can choose more than one answer.

Questionnaire items

18. TBLT requires much preparation time compared to other approaches

19. TBLT gives much psychological burden for teachers as facilitators

20. Materials in the text book are not proper to use TBLT

21. Large class size is an obstacle to use TBLT

22. I have difficulties in assessing learner task-based performance

23. I have limited target language proficiency

24. I have little knowledge of TBLT

25. TBLT is not useful for exam preparation

26. Others (Please specify)

That is the end of the questionnaire. Thank you so much! 